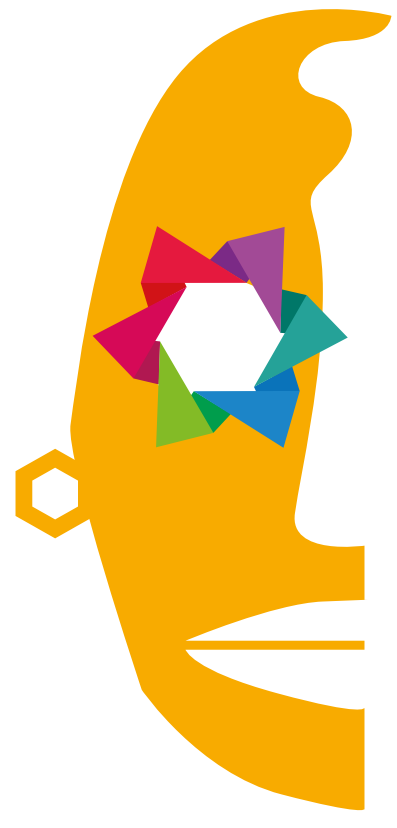

Rafael Lara-Martínez Department of

Communication, Liberal Arts, and Social Sciences New Mexico Institute of Mining and Technology Socorro, New Mexico, Estados Unidos

\section{Fronteras de la Nueva España entre Aztlán (NM) y Cuzcatlán (SV)}

\section{Resumen:}

Nuevo México y Centroamérica se unen por una historia pre-hispánica y colonial común. Mientras las lenguas yuto-nicaraos se expanden de Utah, EE.UU., a Nicaragua, los peregrinos del Cristo de Esquipulas viajan desde El Trifinio (Triángulo Norte de Centroamérica) a Chimayó (NM). Se exploran ambos bordes de un antiguo Virreinato al revelar su enlace por un Camino Real (entre realeza y realidad), cuyas señales olvidadas solo las reconoce una deposición testimonial subjetiva. En primer lugar, una crónica personal desglosa la extrañeza hispana ante su propio legado en EE.UU., el cual los emparentaría con el Sur. En seguida, el ensayo comenta los enlaces culturales y lingüísticos ancestrales que mantienen tradiciones comunes - irreconocidas por nacionalismo cívico - entre el suroeste de los EE.UU. y el triángulo norte de Centroamérica.

Palabras clave: Crónica, historia cultural, Lingüística, migración, mitos
Abstract:
New Mexico and Central America are united by Pre-Hispanic and Colonial history. While Uto-Nicarao languages expand from Utah to Nicaragua, the Christ of Esquipulas' pilgrims travel from El Trifinio (Central America Northern Triangle) to Chimayo (NM). "Bordering the New Spain. Between Aztlán (NM) and Cuscatlán (SV)" explores both sides of an ancient Viceroyalty to unveil a Camino Real (Real and Royal Road) whose forgotten signs are recognized only by subjective deposition. In the first place, a personal chronicle explains Hispanic admiration to their own legacy in the USA, which would connect them to the South. Afterwards, the essay comments ancestral linguistic and cultural bounds - forgotten by national history and civism - between the southwest of the USA and the northern triangle of Central America. 
Keywords: Chronicle, Cultural History, Linguistcs, Migration, Myths

\section{Crónica}

Esta conferencia prosigue el formato de una crónica, uno de los géneros literarios e historiográficos menos estudiados ${ }^{1}$. Su falta de reconocimiento deriva de la ambigüedad misma de la etimología. Cronos significa "tiempo", pero no refiere solo el tiempo del reloj - "what time is it?"- sino el tiempo vivido de quienes participan en el acto de habla. "We are having a good time", sin que los relojes sonrían ni alteren su ánimo. Igualmente sucede en español que bajo esa palabra engloba el clima y el tiempo gramatical (tense). Esta doble vía del sonido hacia el sentido la refiere el pintor chileno Matta en su óleo "Atormentando la tormenta" - el tormento (clima psíquico) y la tormenta (clima natural) - para quien el "surrealismo" es el "realismo del sur". Acaso, se anota en breve, el tiempo refiere una distensión del alma-psique-energía humana que se proyecta hacia lo natural y lo transforma. No en vano, el inglés hace de los fragmentos temporales vividos una posesión del sujeto, de manera idéntica que las pertenencias de objetos materiales: "I had a nice day/shirt/lunch; how is your day/book/lunch?".

De hecho, la crónica define uno de los géneros historiográficos fundadores de América, ya que los frailes la utilizan al recolectar información primaria. Se dan cuenta que la historia no es solo un hecho objetivo, sino se perfilan a sí mismos en el centro de ese acontecer. Ellos mismos se hallan inmersos en el tiempo y actúan en la historia al escribir crónicas. El historiador es un ente histórico que relata su propia vivencia, a la vez de narrar lo que ocurre a su alrededor. Este método resulta tarea habitual en la antropología que exige un trabajo de campo, aun si no todos los investigadores publican diarios que relaten su rutina. En cambio, ocultan la vivencia y prefieren elaborar libros que exponen los resultados, sin aclarar el arduo proceso de experiencias personales en la recolección de los datos. En este instituto tecnológico, la usanza más familiar la ofrecería la vivencia de un ingeniero petrolero, quien describe las peripecias de su viaje a los terrenos de explotación, antes de redactar un reporte técnico. A semejanza del ensayo clásico, la crónica no solo relata los resultados objetivos y convencionales de la investigación. También esboza la trayectoria conflictiva, los errores y los varios incidentes cuyo recorrido concluye en un producto racional elaborado. Sin abstracciones, lo

1 Esta conferencia fue impartida en inglés - Macey Center, New Mexico Tech (Leroy Place, Socorro, NM 87801) 12 April $2107 @ 7 p m-y$ publicada en español en el libro "Los ensueños del escombro", San Salvador: Universidad Don Bosco, 2018. Por esta razón oral, el estilo se acerca más a la lengua hablada dirigida a un público general que a un escrito académico orientado hacia especialistas. Además de la bibliografía, la información citada la fundamentan veinticinco (25) años de residir en Nuevo México, donde he visitado todos los lugares comentados en el ensayo. Se trata de una antropología de campo que relata vivencias y entrevistas informales cotidianas con personas de distinto estrato social. 
objetivo e imparcial los decide el objetivo que establece el sujeto en su colecta (logos) parcial del mundo material.

Figura 1. Carátula de una crónica colonial

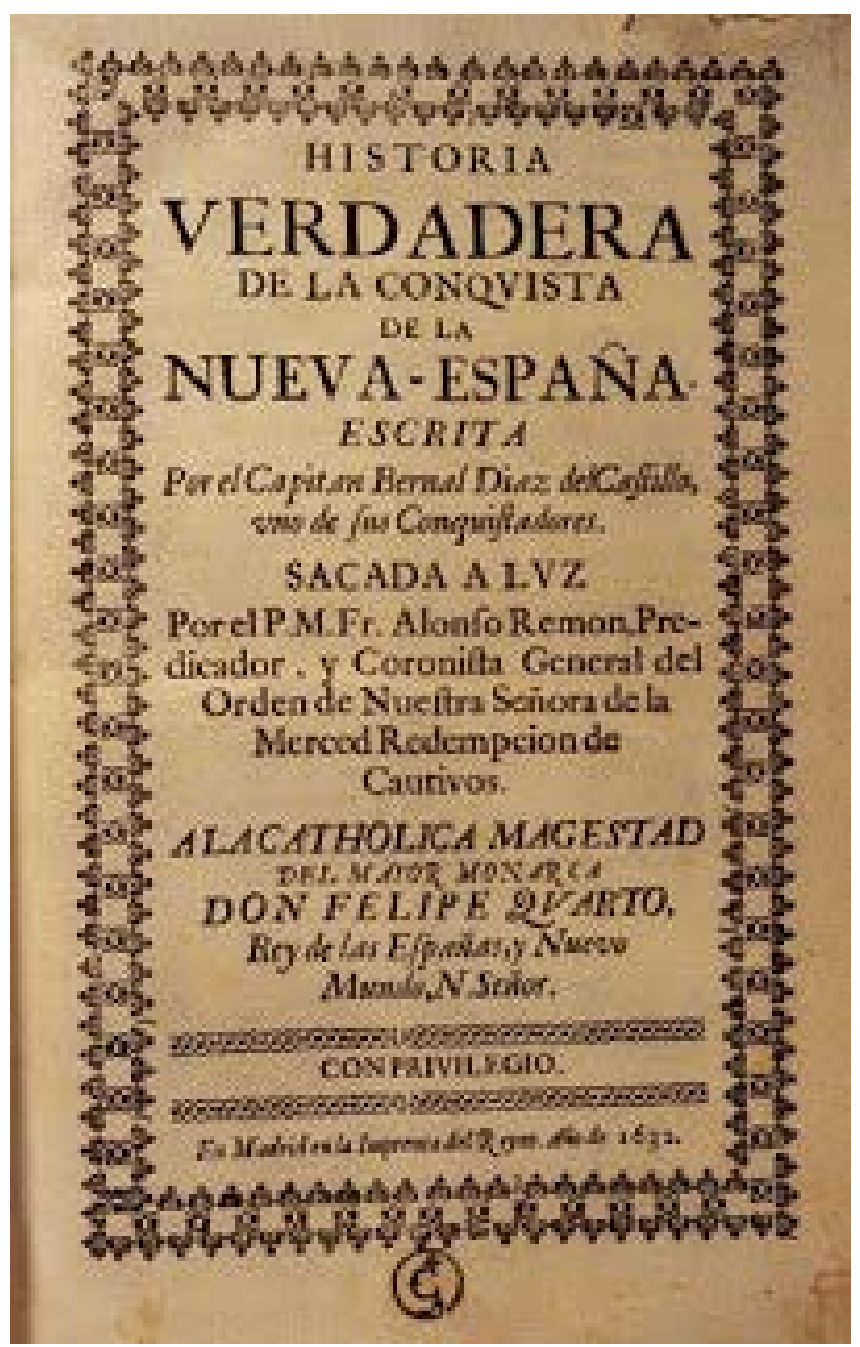

Fuentes: https://www.christies.com/lotfinder/Lot/diaz-del-castillo-bernal-ca-1492-1581-historia-6012502-details.aspx / , https://blogs.lib.utexas.edu/texlibris/2018/09/05/collections-highlight-historia-verdadera/

$* * * * *$

La conferencia se divide en cuatro partes. De manera anecdótica e interpretativa, la primera relata mi experiencia inicial de recepción en Nuevo México. Subraya la manera en que los hispanos de EE.UU. a menudo no perciben una continuidad 
histórica ni cultural entre el suroeste del país, México y el triángulo norte de Centroamérica. Por fines nacionalistas, la historia les enseña que Nuevo México comparte un pasado común con la Nueva Inglaterra (Saint Patrick Day, Independence Day, Halloween, Thanksgiving, etc.). La negación primera de toda herencia indígena, la reitera el intento de borrar toda traza de una Nueva España colonial que vincularía el suroeste de los EE.UU. a sus vecinos cercanos. Ese recuerdo haría que la frontera actual se volviera permeable y arbitraria, en vez del muro ideológico que la historia cívica anhela edificar. A explicar esta herencia indígena y nuevo-española —olvidada adrede — se dedican las secciones siguientes.

\section{Llegada}

Llegué a Nuevo México hace veinticinco años. Unos tres o cuatro años después fui a la biblioteca de la Universidad de Nuevo México, en Albuquerque, a consultar bibliografía. Al acercarme a la recepción, luego de platicar un rato con dos bibliotecarios, uno de ellos me preguntó. "¿Qué hace Ud. aquí tan lejos de su patria (homeland)?" Al observar su apellido, marcado en el pecho anoté lo familiar: "Sánchez". A su lado, la colega se apellidaba "Romero". Al advertir lo conocido, en silencio me interrogué: ¿Sánchez y Romero? Si los tradujera al inglés, el primero sería hija de Sancho, quizás de Sancho Panza, la figura literaria de mayor renombre, es decir, Humpty Dumpty.

Me parecía absurdo que una persona oriunda de Massachusetts le replicara lo mismo a otra del Sur de Carolina. Los seres imaginarios del Reino Unido solo se habrían arraigado en el noreste, mientras el sureste permanecía ajeno a toda experiencia colonizadora. Mis interlocutores pensaban que lo mismo había ocurrido con la herencia ibérica, la cual solo permanecía vigente en Árido América. En inglés, el segundo apellido rezaría "rosemary' o "pilgrim". Dudaba que esa planta solo creciera en Nuevo México y que las romerías solo llegaran a estos rumbos nórdicos. A mi afán traductor — pues hablábamos en inglés - añadía el sinsentido de concebir que los mismos patronímicos se juzgaran extranjeros a uno u otro lado de una frontera trazada hace un siglo.

Mi respuesta acallada por años la ofrece esta conferencia bastante tardía. Yo había nacido más allá de la frontera sur de la Nueva España y aquí vivía en la frontera norte. Creía hallarme hacia la esfera boreal de mi propio país como si, por simple unión de contrarios, el trópico cálido y poblado se diluyese en el árido desierto. La humedad en su antónimo de sequía. Sin embargo, esta antigua correspondencia de los complementarios ya no se vislumbraba como tal. Por las nuevas fronteras nacionales y la educación cívica, los Sánchez y Romero norteños se percibían más cercanos a los pobladores de la Nueva Inglaterra que a sus homónimos del sur. Esta concepción no me parecía descabellada al pensar que la distancia no la 
medían los kilómetros ni las millas. La tanteaba el recorrido inventado por una cultura nacional en boga. En esta comarca, mi familia materna se juzgaría más que extranjera - alienada, por la glosa literal del inglés alien - pero la gobernadora de igual apellido se arraigaría en este sitio como oriunda desde su origen.

Figura 2. Mapa de la Nueva España

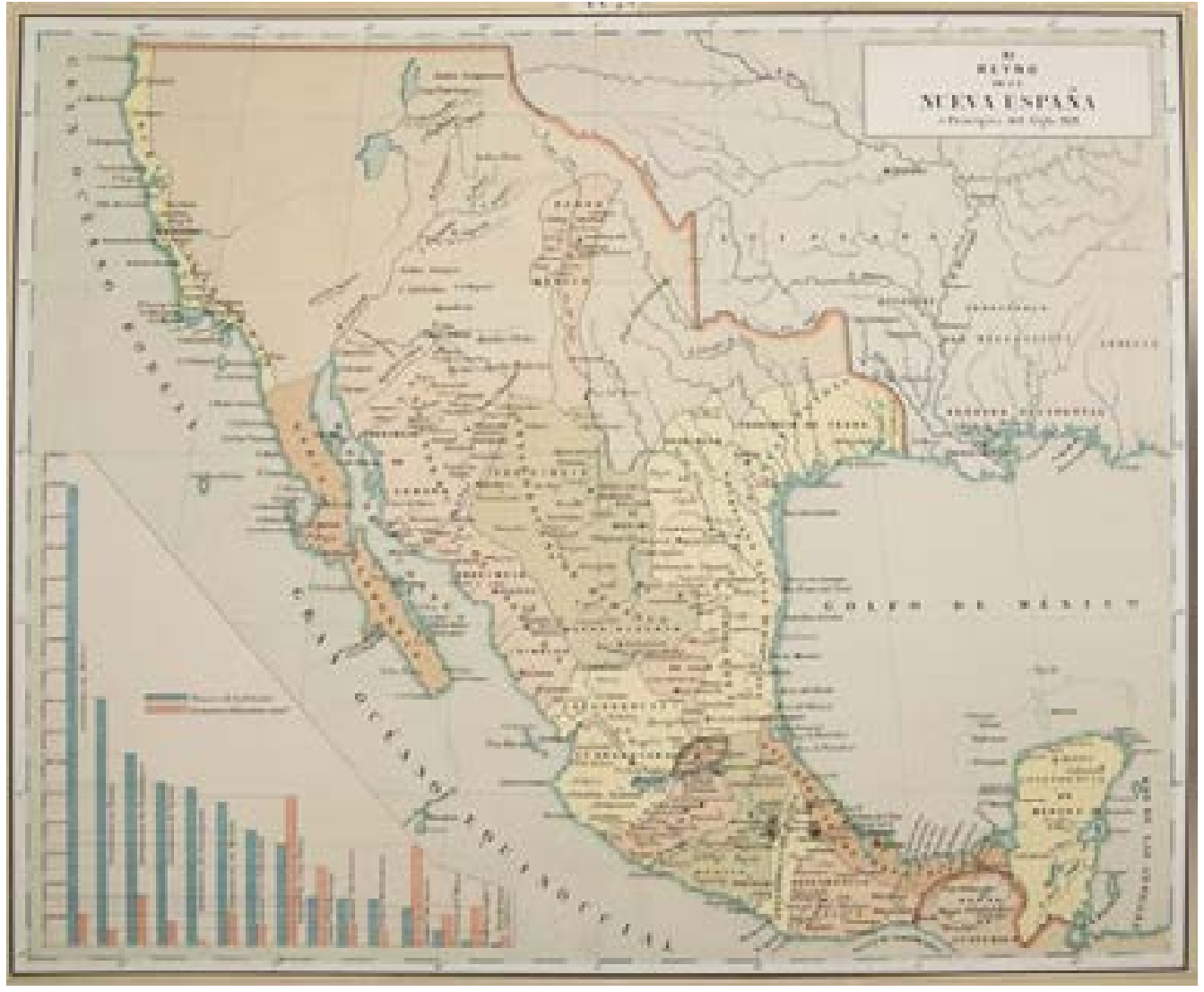

Fuentes: $\quad$ https://upload.wikimedia.org/wikipedia/commons/8/84/Reyno_de_la_Nueva_España_\%28Siglo_ XIX\%29.JPG/,http://www.espejel.com/el-atlas-geografico-de-antonio-garcia-y-cubas-mexico-en-1858/.https://www. davidrumsey.com/luna/servlet/detail/RUMSEY 8 1 272478 90046284: Carta-general-de-la-Republica-Mexic

"Nada nuevo bajo el sol", pensé. En ese instante, dictaminé que el espacio se calculaba de manera semejante al tiempo. Más que una dimensión en números objetivos, el sujeto hablante los evaluaba a partir de su experiencia presente. Sánchez y Romero me repetían el capítulo XI de "Las Confesiones" de San Agustín, actualizado por M. Heidegger y P. Ricoeur en el siglo XX (véase: referencias bibliográficas). Según su postulado, el emisor se hallaba siempre al centro del acto de habla en su Yo-aquí-ahora. Antes que personas individuales, ambas me 
interrogaban como ciudadanas estadounidenses. Pensé que así definían su subjetividad. Si el pasado y el futuro - will en inglés - los determinaban una intensión y distensión del "alma" — psique, mente, etc. — de igual manera sucedía con el espacio. En un sentido rígido, bajo el sujeto individual - Mr. Sánchez; Ms. Romero - se desplegaba el ciudadano de una república actual. Bajo (sub-. under) el individuo se lanzaba su calidad de elector y súbdito de una comunidad. Solo en seguida de aceptar esta nacionalidad, el individuo se asumía en cuanto tal, persona independiente. Previo a cualquier opción activa — "ser sujeto" - se era miembro pasivo de una comunidad actual de origen - "estar sujeto". Después de esta filiación nacional, el sujeto podía volverse deponente testimonial de esa cultura.

El inglés - discurría - calcaba esta vivencia paciente original al describir el nacimiento en una oración pasiva: "I was born/carried/hit". Nadie nació, sino el nacimiento vino a sí - lo trajo al mundo sin preguntárselo, a un espacio-tiempo no elegido - como un sueño o embate, hasta adjudicarse una personalidad propia dentro del rebaño. Por este gran daño, la sociedad se renueva o, excluye toda osadía individual que remite al ostracismo. En uno de los múltiples pasos del "estar" al "ser".

Por principio natal, la criatura brotaría siempre en una comunidad de la cual aceptaba la lengua materna, la cultura y la herencia ancestral, previo a su madurez personal. Desde esta aceptación inicial, el Yo-aquí-ahora hablaría según una memoria del pasado y una expectativa nacionalista futura. En el caso preciso de Nuevo México, por la decisión ciudadana que subtendía a Sánchez y Romero, ambas familias se encontraban más cercanas de los peregrinos de la Nueva Inglaterra que de sus parientes lejanos de una Nueva España, ahora en el olvido. La construcción social de la memoria obligaba a inventar nuevos mitos de origen para consolidar el nacionalismo en boga. Se conservaba la memoria de la Nueva Inglaterra, a la vez que se desdeñaba el recuerdo de la Nueva España. Acaso tal duplo recuerdo-amnesia sería un requisito indispensable de la nacionalidad estadounidense actual, por una recolección (logos) selectiva del pasado.

Ante ese vaivén de los opuestos complementarios - memoria y olvido; retentiva y tachadura - comencé a indagar los posibles encuentros entre mi lugar de residencia actual - Nuevo México - y el de mi nacimiento El Salvador, esto es, entre el sitio de mi ejercicio académico activo y el de mi recepción pasiva iniciática. De inmediato hilvané la solución. Ambos territorios se hallaban al margen de dos antiguas regiones políticas y culturales: la Mesoamérica prehispánica y la Nueva España colonial. Sin mencionar la influencia del capital financiero actual. 


\section{Desglose}

Esta vivencia ancestral compartida la glosan el título y el subtítulo de la conferencia en curso. Prosiguiendo la idea agustiniana del tiempo, me muevo del presente hacia el pasado, al transcurrir por esa vía subterránea de la herencia que respalda a mi persona individual. Por ello, el título anticipa la colonia, antes que el subtítulo anuncie lo prehispánico, ya que me desplazo progresivamente hacia lo remoto. Como el trabajo historiográfico, el itinerario avanza del presente al pasado, en un "viaje a la semilla" (1944) carpenteriano, predicho por Brígida en "El árbol" (1941) de la chilena María Luisa Bombal. En términos derridianos clásicos, el recuerdo y la recolección de documentos primarios presupone un "mal de archivo" (1994), en el cual "la experiencia de la memoria" la regula "la autoridad (el arconte)" quien decide "el lugar" que salvaguarda la huella del recuerdo. Precisamente, a esta ocupación se dedica la historia nacional y cívica que este ensayo cuestiona ${ }^{2}$.

$* * * * *$

El Salvador formaba parte de la Capitanía General de Guatemala, hacia el confín del Virreinato de la Nueva España, mientras Nuevo México constituía su límite norteño. Ambas comarcas las unía el Camino Real que ninguna imagen actual del internet reproduce, acaso por olvido voluntario. Tampoco la historia cívica de este estado lo conmemora al detener el trayecto en el altiplano central de México. Al recuerdo de una sola vía de la capital de la Nueva España - la ciudad de México - hacia el norte, se contrapone su apertura hacia el resto del mundo, ya globalizado. El verdadero nombre de este Camino Real inadvertido correspondería al del puerto de entrada de los españoles a tierra firme: Veracruz. El camino en cruz - el camino o la vereda de la cruz - no solo recobra un significado religioso, como el que esta Semana Santa emprende la romería hacia Chimayó, al norte de Nuevo México, de la cual hablaré en seguida. También conlleva un sentido comercial de intercambio de productos que fluyen hacia la metrópolis, provenientes de las cuatro esquinas del mundo imperial. Así lo describe el recuadro siguiente, sin incluir la América del Sur. Mundo global e imperial antes de la globalización actual.

- Nuevo México

\section{Filipinas $\rightarrow$ México $\rightarrow$ España}

- Guatemala

2 En términos de oposición complementaria norte-sur, al optimismo de la memoria histórica en Norte América se contrapone el pesimismo argentino y uruguayo. Mientras Juan Carlos Onetti declara "las embellecidas memorias, falsificadas por necesidad" (1973, p. 24), Ernesto Sábato confirma que "no hay memoria colectiva... forma de defensa de la especie humana" (1985, p. 61). 
Figura 3. Misiones de los Pueblos Salinas, Nuevo México

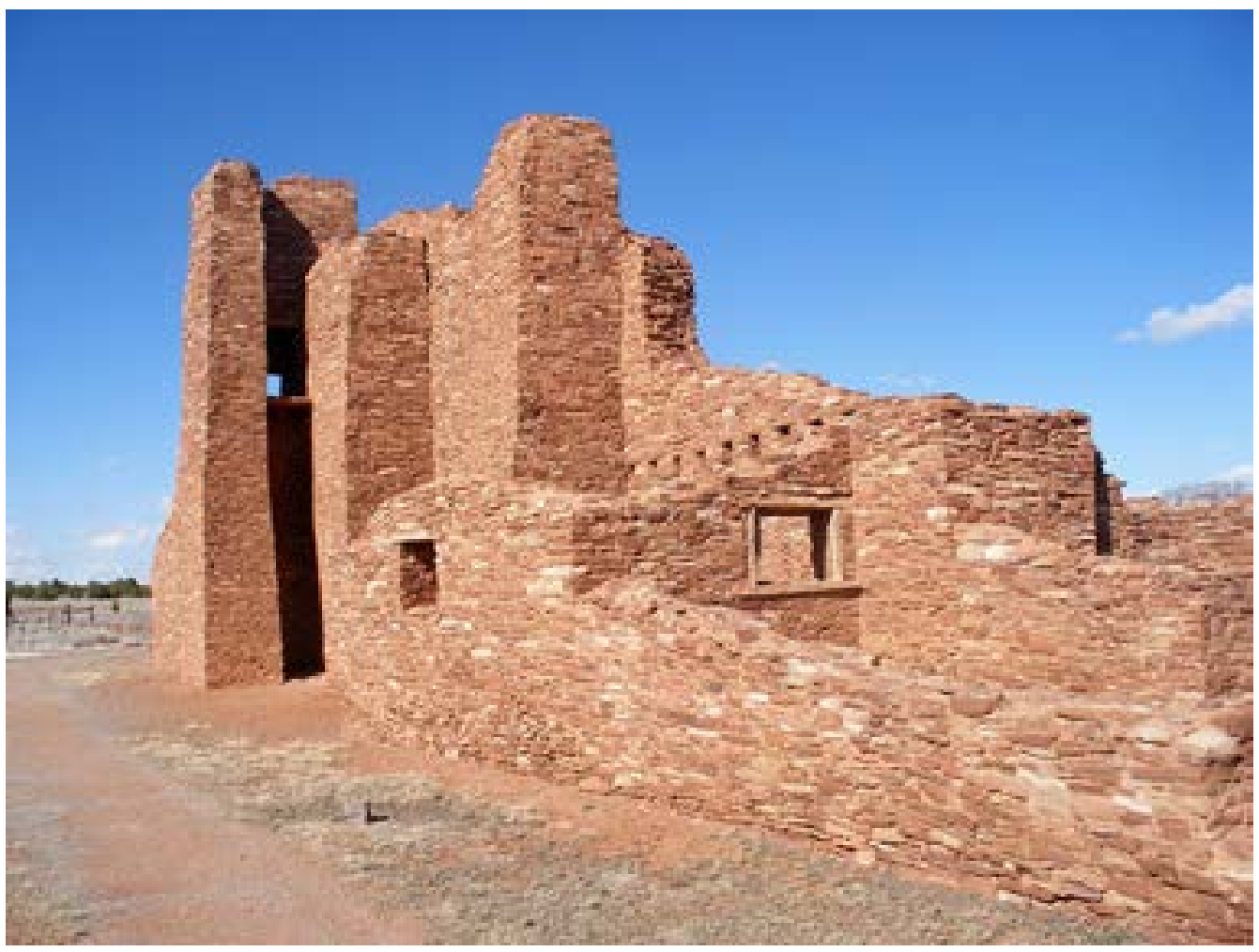

Fuentes: https://www.alamy.es/foto-ruinas-de-la-iglesia-monumento-nacional-salinas-pueblo-misiones-nuevo-mexico-eeuu-79762156.html/, https://es.dreamstime.com/imagenes-de-archivo-ruinas-del-abo-image26565014

La evidencia de esta conexión se halla presente en el paisaje de ambas comarcas. En El Salvador, puede visitarse Ciudad Vieja, en Nuevo México, las Misiones de los Pueblos Salinas: Abó, Quarai, Gran Quivira. Asimismo, la memoria la expresan topónimos castellanos como el de este pueblo - Socorro- que no significa "Help" como se traduce oficialmente, ya que conlleva una idea sobrenatural, de redención religiosa o de peligro extremo, también postergada por razones nacionalistas. En cambio, replicando el sentido del concepto de sujeto - lo que se tira bajo (sub-/under) - socorrer se descompone de igual manera: lo que corre bajo (sub-/so-). Esto es, el espacio-tiempo-energía que se recibe al nacer, el cual a cada instante lo renueva el Yo-aquí-ahora, de manera personal y social. Esta evidencia del panorama mismo testimonia el paso de los ancestros muertos - the ones who passed by/away - por un territorio. No somos Adán y Eva, los primeros habitantes de esta comarca sellada de huellas antiguas, donde aún palpitan fábulas vivas. En griego, el descifrar estos vestigios se glosaría geografía o escritura (grafos) de 
la tierra (geo); en latín, leyenda o lectura que el presente realiza de los indicios indelebles del pretérito, sea para conservarlos o tacharlos. El entorno se halla marcado por la inscripción — por la escritura jeroglífica - de los ancestros, se reconozcan como tales o se desdeñen por nacionalismo en boga.

Asimismo, se lee el subtítulo el cual enuncia los dos nombres indígenas de las comarcas de esta conferencia: Aztlán y Cuzcatlán. Ambas regiones las une un nuevo sentido del lugar que lo enuncia la terminación común: -tlan, "en el lugar de". Si el primer topónimo designa el sitio mítico del cual emigraron los aztecas hacia el altiplano central, el segundo señala la región de llegada de los náhuat-pipiles a El Salvador actual. Existe una gran controversia sobre el inicio de ambos topónimos —aztatl, "garza, blanco", aztayo, "esclavo, sirviente"; "cozcatl/cuzcat", "niño, joya"- que unifica el sufijo terminal locativo3.

Figura 4. Tira de la peregrinación mexica

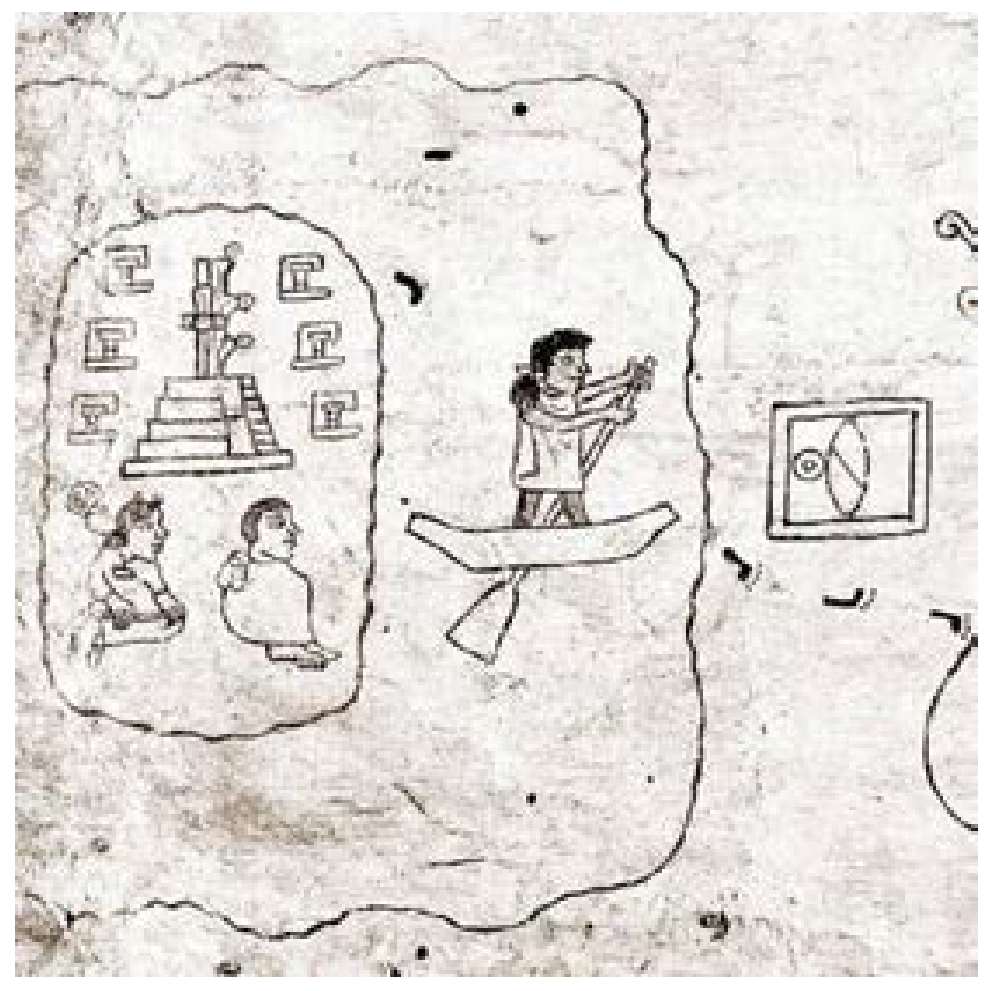

Fuente: https://arqueologiamexicana.mx/mexico-antiguo/tira-de-la-peregrinacion-la-ascendencia-chichimeca-de-los-mexicas /

3 Véanse los diccionarios citados en las referencias bibliográficas. 
No obstante, la indecisión actual la solventan otros dos topónimos vinculados a la experiencia azteca. Estos locativos nos enseñan que - sea cual fuese la versión literal-interesa rastrear el simbolismo mito-poético que la subtiende. De nada serviría asegurar que el único sentido preciso de Aztlán es "en el lugar de las garzas" o "en el lugar de lo blanco", etc. —el de Cuzcatlán, "en el lugar de joyas o de progenie" - si se ignora la hermenéutica de esos términos literales en el pensamiento indígena ancestral. Al expresar lo literal de una metáfora incierta, se generan nuevas ficciones que ahora se revisten de técnica, al solapar su actualidad eficaz.

A este respecto, confirmo, resultan ilustrativos otros dos topónimos relacionados a los aztecas, a saber: Chicômôztoc y Mêxihco. El último nombra este territorio. Pese al debate por el segundo término, ambos se unifican en su referencia al cuerpo humano mismo. Si el primero glosa "en el lugar de (-c) las siete (chicôme) cuevas (ôztotl)"; el segundo quizás, "en el lugar del ombligo de la luna". Aun si la localización geográfica exacta parezca aleatoria, puede certificarse que las "siete cuevas" remiten a los orificios del cuerpo humano: ojos (1), oídos (2), fosas nasales (3), boca (4), ombligo (5), ano (6) y uretra (7). Acaso su mención indique el origen de la vida, es decir, el ingreso del espacio-tiempo-energía (Tonalli-Yollotl-Ihiyotl) al cuerpo biológico que le sirve de cascarón (ixiptla) durante su paso efímero por la superficie de la Tierra.

Asimismo, la etimología más aceptada de México relaciona el locativo al ciclo femenino, es decir, a la Matria (homeland) originaria del ser humano y a su tatuaje de marero original, el ombligo. En verdad, si la luna (mêztli) remite a la menstruación (mêtzuia) -al vientre materno como alcoba líquida de los inicios- el ombligo imprime la circuncisión primordial del cuerpo. Estipula un "tatuaje" original — un principio, inicio y axioma - anterior al archivo que J. Derrida reconoce en el recorte judaico de la ley. El niño jamás nace desnudo, sino emerge recubierto de placenta que se le extirpa y del cordón que se le cercena a la llegada. Ambos topónimos remiten al exilio del alma - energía divina (Tonalli-Yollotl-Ihiyotl) — en el cuerpo biológico humano. Esta salida de una cueva (ôztotl) sella su única manera de otorgarse un hogar temporal en la Tierra. En términos mediterráneos sería un "viaje a Ítaca" — como el griego K. Kavafis llama a la vida - mientras el México antiguo reitera ese éxodo de la energía anímica que - desde el inframundo - cual semilla brota en un cuerpo, luego de su captura durante la gestación.

Quizás, en EE.UU., la famosa novela anglo-americana de Thornton Wilder Heaven's my Destination (1935) - insinúe esta visión atávica que, en su época, desglosa la convicción de transcurrir por el mundo como forastero en éxodo interminable. Hasta honrar el título al lograr que la muerte clausure el retorno a la 
Matria, al Homeland tan añorado. En la lengua náhuat de El Salvador, la sinonimia de "enterrar" y "sembrar" - tuka - acentúa la manera en que la unidad indisoluble cuerpo-alma la recicla el terruño. Según el vaivén de las estaciones, la experiencia de vida prosigue un tiempo circular infinito del retoño (spring) al otoño (fall).

El hondo sentido del lugar lo determina el sufijo terminal que concluye todo topónimo, tal cual los locativos antes mencionados: -c, -co, -tlan, etc. La connotación del lugar consigna dos adagios castellanos, difíciles de traducir al inglés. Si por tradición clásica este idioma declara "to be or not to be" - sin referencia al sitio de la existencia - la lengua materna me obliga a explicitarlo. "Ser es estar (Being is Dasein)", es decir, el ser lo modifica su localización precisa en un espacio-tiempo, en la historia que lo altera. Sirva la imagen de Monseñor Romero - arzobispo de San Salvador, hoy santificado - en ejemplo de tal postulado. Durante la guerra civil salvadoreña aseverar "no matarás" se convierte en un postulado comunista al salvaguardar la integridad física del presunto enemigo del gobierno. El trabajo que en EE.UU. se llama "community service" se interpreta, de manera oficial, en comunismo. Por ese "ser" que "está" en un sitio preciso, en un justo momento de la historia. Igualmente, este sentido del lugar sustituye el "I know by a fact" que reiteran las noticias televisivas en EE.UU., por una doble manera de "knowledge" que desdobla el saber en conocer. Sin incluir la llana sabiduría (wisdom). Valga un simple ejemplo. Si un ginecólogo sabe de gestaciones, jamás las conocería en vivencia propia para escribir la crónica testimonial de su embarazo. En este instituto tecnológico, los hallazgos de laboratorio los vuelve efectivo la aplicación comercial y política en un Espacio-Tiempo determinado. La fórmula universal la relativiza la práctica que la ingeniería de petróleos certifica al trabajar en Texas, Venezuela o Irán.

\section{Desenlace}

Este doble vínculo del estar y del conocer arraiga el título y el subtítulo en su verdadero trasfondo filosófico. La conferencia prosigue la idea de una crónica en la cual el tiempo lo mide la tensión — tension and tense in English - de mi propio espíritu - my mind, in current English folk terminology — hacia el pasado latinoamericano de estas regiones del suroeste estadounidense ${ }^{4}$. Utilizando un concepto inglés - to realize - testifico que lo Real solo se vuelve realidad en el instante en el que una persona o grupo lo asume como tal, ya que la creencia guía

4 La indistinción entre "time" y "tense" en inglés coloquial la expresan los hablantes, quienes perciben el "tiempo (time)" como una flecha en continuo del pasado hacia el futuro. La idea de un presente continuo -marcado por el Yo-aquí-ahora - solo la aceptan a posteriori en el asombro. Lejos de toda prescripción lingüística, en Nuevo México se aplica la idea de Steve Miller Band en "Like an Eagle": "Time keeps on slippin', slippin', slippin' into the future". 
la visión tal cual sucede por siglos con los astros: Venus, dividida entre Nextamallani matutina y Xolotl vespertino.

Entiendo que la cultura latinoamericana se caracteriza por una idiosincrasia híbrida que mezcla la diversidad indígena con la ibérica en un todo único. Desde esta perspectiva - la de una memoria colectiva y subjetiva - rescato rasgos distintivos muy disímiles que las cualidades nacionales que al presente vinculan Nuevo México a la Nueva Inglaterra. Sánchez, más cercano de Humpty Dumpty que de Sancho Panza; Romero, de los pilgrims que de las romerías. En esta recolección (logos), la invención del pasado da cuenta — realizes - que la memoria ante todo sirve a la expectativa, a la voluntad (will) de un futuro (it will) nacionalista, más que a una fidelidad factual. El anhelo presente de un porvenir imagina el pasado a su imagen y semejanza.

Así ocurre con los tres términos que designan en EE.UU. al grupo de origen español: hispano, latino y chicano. El primero se usa en Nuevo México sin referir la variedad cultural de la península - castellana, catalán, vasca, gallega, gitana, sefardita, mozárabe, etc. Basta mencionar que el nombre propio de la Virgen de Guadalupe, reconocida por su raigambre indígena, proviene de una palabra árabe - tal como Guadalquivir, Guadarrama - para asentar lo complejo de la herencia hispana, que anhela olvidar ciertas facetas de su pasado (véase: Lafaye, 1977). El segundo - latino - embrolla aún más la herencia ya que obliga a incorporar otras naciones actuales, también diversas: Portugal Francia, Italia. Por último, el término reciente de chicano - neologismo de mexicano, xicano- afirma su deseo re-volucionario, en el sentido estricto y antiguo que pretende retornar a los orígenes denegados.

Sin mencionar otras tradiciones como la asiática, la africana e incluso la anglo, me limito a reiterar la doble herencia indígena e hispana que une este territorio norteño de la Nueva España a su costado sureño exterior. La noción arquetípica la proclama el proceso de migración el cual representa - a nivel de lo imaginario- un elemento clave de una Tabla Periódica Universal, semejante al Alfabeto Fonético en su aplicación obligatoria. Habría una determinación estricta de lo imaginario, así como existe una precisión de los sonidos posibles de toda lengua. Como el libro del Éxodo, los diversos grupos indígenas emigran hacia la Tierra Prometida guiados por su Divinidad Protectora. Incluso, de retomar el concepto mexica, la migración forja un Destino Manifiesto - Pueblo Elegido a conquistar el resto-que los EE.UU. reiteraría en el siglo XIX. La migración indígena ocurre del norte al sur; viceversa, la hispana, de sur a norte.

La lingüística histórica comprueba la existencia de una familia de lenguas yuto-nicarao (véase L. Campbell). En inglés aún influye la tradición colonial que 
Figura 5. El Santuario de Chimayó, Nuevo México

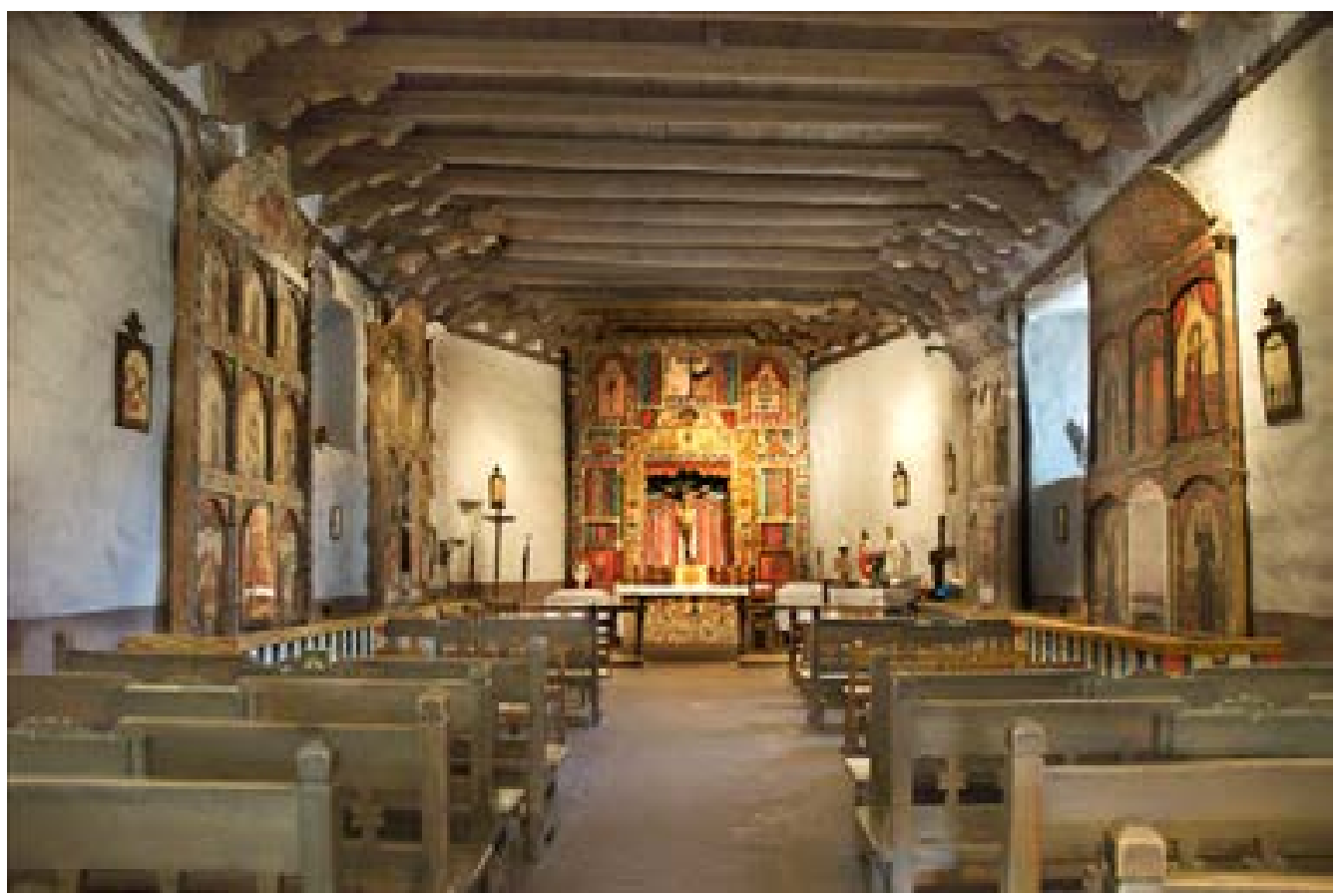

Fuente: http://chimayo.us/PC/Points.html

asimila las ramas sureñas, al prestigio del altiplano central mexicano, al llamarla Uto-Aztec Languages. La distinción entre el náhuatl-mexicano, el náhuat-pipil y el náhuat-nicarao no resultan tan convincentes como la asimilación de las hablas de menor prestigio a la hegemónica. Esta pauta deriva de la idea colonial que clasifica las hablas centroamericanas como mexicano vulgar, en vez de reconocer su autonomía, donde "vulgar" traduce al latín el término "demos" del griego. Por designio colonial, el náhuat-pipil y el nicarao correspondería al náhuatl-mexicano del pueblo rústico, en discrepancia al urbano y noble. La migración más conocida la representa la de los mexicas hacia el Altiplano central. Empero, se argumenta que existen éxodos sucesivos hacia el sur, tal cual el de los náhuat y nicaraos antes incluso de la llegada de los mexicas al centro de México.

Estas peregrinaciones invierten su sentido durante la colonia, remontando por el referido Camino Real en crucero. Una de las primeras figuras a recorrer esta vía se llama Cihuacoatl, uno los múltiples nombres mexicas de la Diosa Madre (véase: B. de Sahagún). Hacia el sur se le conoce con el calificativo indígena castellanizado de Siguanaba; al norte como La Llorona. Su presencia dilatada a todo lo largo del eje central del Camino Real testimonia la permanencia de un área cultural, por el recuerdo de los Seres Imaginarios. Estos Entes Ficticios no 
se doblegan ante el simulacro técnico a la moda ${ }^{5}$. Seductora al sur, abandonada al norte, su silueta niega rendirse ante la nueva mitología de la ciencia, hecha hoy de fábula industrial.

Su hijo - Cipitío o Cupido tropical; niño ahogado al norte - denota la actitud divergente hacia el mestizaje y hacia la colonización. Mientras Nuevo México replica el abandono de los Dioses a su progenie sumergida en el río - metáfora de la conquista espiritual — más benigno, el sur moldea la imagen de un Cupido que lanza flores y guijarros a las hembras, incitándolas a enamorarse. El verdadero sentido de un mito exige - no aislar una versión de la otra- sino contrastar acuerdos y divergencias, en un Camino Real ahora interrumpido por muros, historias cívicas y fronteras nacionales.

Figura 6. Tomé Hill, Belén, Nuevo México

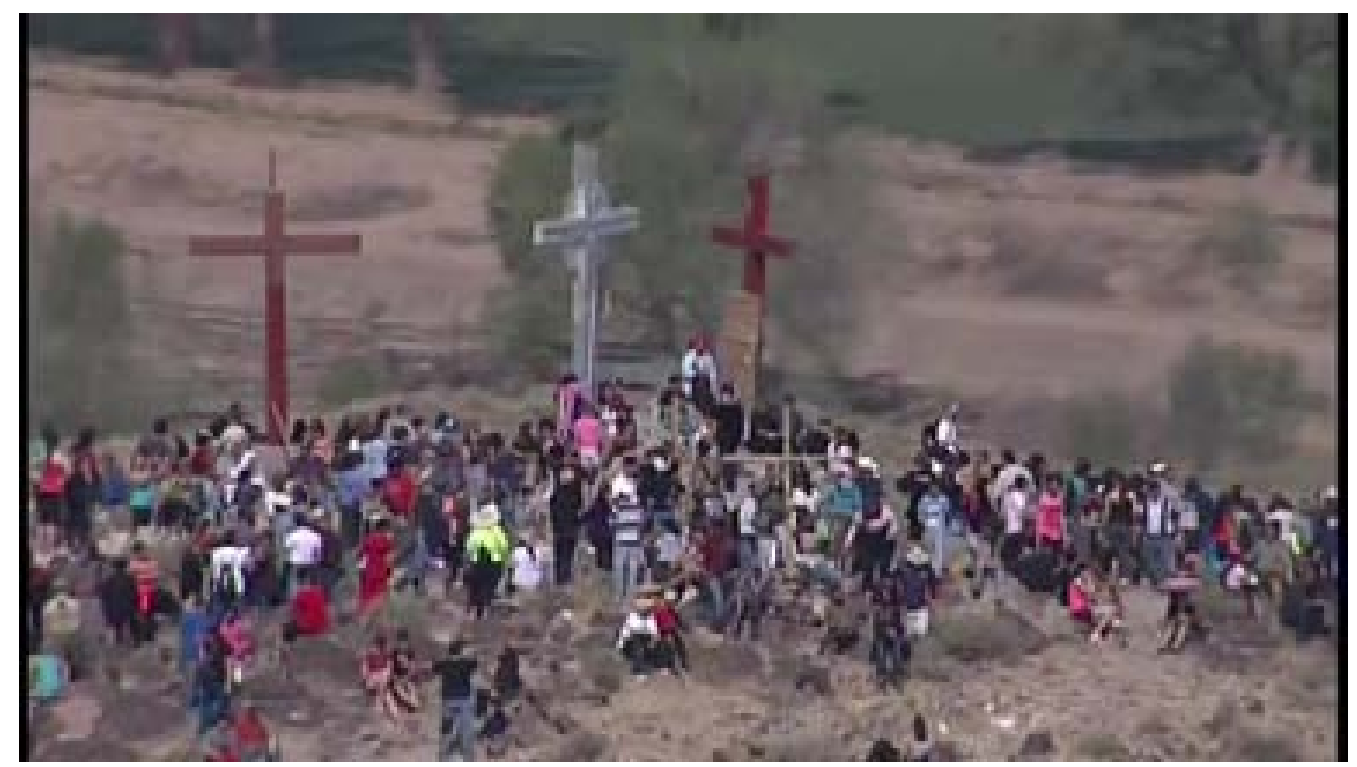

Fuente: https://www.youtube.com/watch?v=wqLTfeUfrTI /

Otra figura colonial común se llama El Cristo Negro. Su diseminación hacia el norte testimonia el potencial mito-poético de la frontera sur mesoamericana (véase: C. Navarrete). Brota en El Trifinio, el único sitio en el cual se reúnen tres países centroamericanos. Ahí se levanta la antigua urbe de Copán en Honduras; el santuario en Esquipulas, Guatemala, y el bosque nebuloso en El Salvador. La controversia de su etimología resulta tan intrincada como la de su color oscuro.

5 Véase afición por la ciencia-ficción y sus disfraces entre los estudiantes científicos como nueva mitología, evolutivamente correcta. Vestirse a la "Star Wars" y usar un idioma fílmico se perciben como adecuados a la técnica actual, mientras se incita al olvido del Otro realmente existente: indígena e hispano hablantes. 
Sea que su nombre provenga del castellano escapulario, del náhuatl-mexicano Itz-culti-paloa-c, "Donde las manos labran y reza la obsidiana", asombraría aún más que un nombre de la familia maya se difunda hacia áreas ignotas: Ek Ik Pul Ha, "Negro viento que empuja el agua". A Uds. de buscar otros orígenes que multipliquen las interpretaciones. Por su color, simplemente, podría argüirse la quema de velas en su devoción, como causante del tizne que lo ennegrece. Más complejo, honraría el bronceado oscuro de la población que lo venera. Para complicar el trasfondo ético, una de las novelas de la tercera década del siglo XX, en El Salvador, El Cristo Negro (1927) de Salarrué, estiliza su imagen como "devorador de excrementos". En réplica de Tlazolteotl, no solo absorbe la culpa ajena en confesión, sino realiza sus pecados. El deseo ajeno de maldad lo encarna esa figura diabólica que permite la pureza de la comunidad entera, según el modelo típico de un chivo expiatorio. De esta manera, la exégesis del color desemboca en un cuestionamiento teológico y moral que el simple pigmento del humo evade aludir. En una idea de mito-poética sin ética ni preceptos morales.

\section{Dimisión}

Sería de una crasa ingenuidad creer que las figuras antedichas resultan exclusivas de un flujo constante - a doble vía - en esa vera cruz del Camino Real. Al cauce monetario — sin duda legal — al intercambio militar — siempre justo- no solo les anteceden imágenes religiosas. Como la del santo Niño de Atocha, cruzan fronteras nacionales sin permiso previo. Las naciones ahora se inventan como naturalizaciones de la cultura, al inculcar que sus fronteras territoriales calcan bordes ancestrales. En verdad, no solo esa imagen se desgonza en racimo de su origen hasta transitar de migrante por el crucero referido.

También, desde la guerra civil de los ochenta - la paz de los noventa - las maras (gangs) establecen vínculos globales. Saltean altas bardas para enraizar su identidad transnacional en rizoma de manglar. Se globalizan según lo exige la época. Estos "tiempos de asombro" estrictos reciclan la termodinámica. La ciencia rigurosa aplica el principio que dicta el más desgarrado presente. La violencia no se crea ni se destruye; solo se transforma y la técnica la recrudece, al proclamar la idea de lo Uno sin diferencia. La intensifica la política de la ciencia-ficción en cuya utopía reina el rancio precepto de eliminar al enemigo, en requisito fundacional de la ciudad ideal. Hay que dialogar sin oponente para razonar mejor, donde lo Uno repite el postulado derridiano de la violencia inaugural.

En esta (con)fusión de problemas (inter)nacionales ya no valen muros ni fronteras materiales. Tan inútiles como impedir que la música se propague. Se difunda veloz como el sonido. Solo permanece vigente aquel aforismo medieval que relativiza todo nacionalismo. Lo diluye en lo universal. "Quien piense que su país es 
hermoso, se declara tierno principiante. Quien percibe todo país como el suyo, ha avanzado. Pero sólo la sabiduría vislumbra la Tierra cual país extranjero y de paso hacia lo propio". "Sólo un instante aquí...". "Anduvimos errantes/años años..." (Geoffroy Rivas, 2001, p. 387).

Figura 7. Tlazolteotl

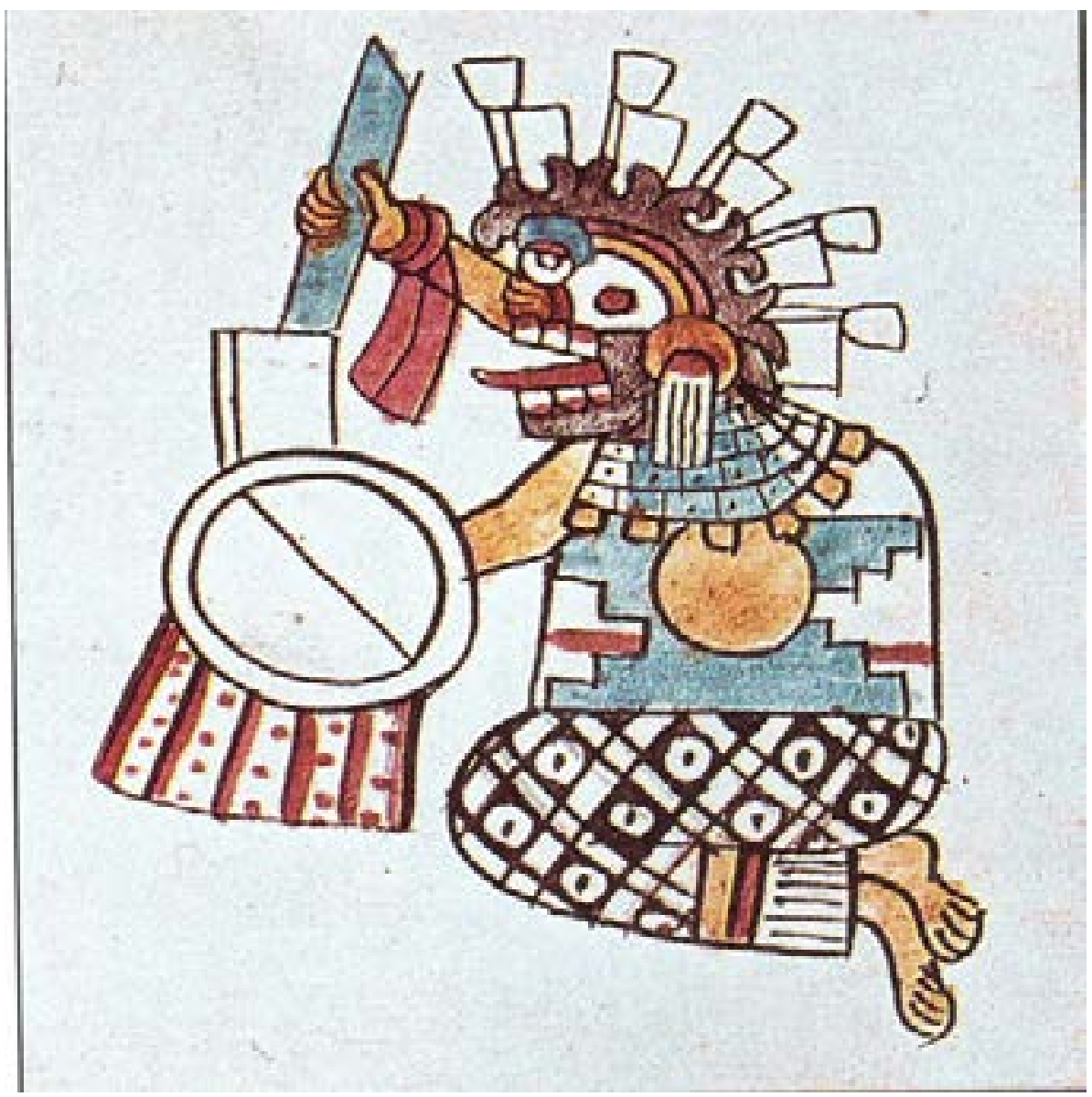

Fuentes: https://www.academia.edu/3315957/Codice_Laud_Digital_facsimil/, http://sacredtoursofmexico. com/tlazolteotl-the-goddess-of-filth/

\section{Referencias bibliográficas}

AULEX. Diccionario Náhuatl. Recuperado de: https://aulex.org/nah-es/.

Bombal, M. L. (1941). El árbol. Recuperado de: https://ciudadseva.com/texto/ el-arbol-bombal/ http://biblioteca.org.ar/libros/323.pdf. 
Campbell, L. (1985). The Pipil Language of El Salvador. The Hague: Mouton.

Carpenter, J. (2015). El camino del norte a Chimayó. An American Pilgrimage. Recuperado de: https://www.americanpilgrims.org/assets/documents/essays/carpenter_camino_norte_chimayo.pdf.

Carpentier, A. (1944). Viaje a la semilla. Recuperado de: https://ciudadseva.com/ texto/viaje-a-la-semilla/

Derrida, J. (1995). Mal de archivo (1994). Paris: Galilée. Recuperado de: https://filologiaunlp.files.wordpress.com/2012/01/maldearchivo.pdf/ https:// redaprenderycambiar.com.ar/derrida/.

Derrida, J. (2002). Trace et archive, image et art. Recuperado de: https:// redaprenderycambiar.com.ar/derrida/frances/trace archive.htm.

Geoffroy Rivas, P. (2001). Obra completa. San Salvador: Dirección General de Publicaciones e Impresos (DPI). Rafael Lara-Martínez (Ed.).

Gran Diccionario Náhuatl. Recuperado de: http://www.gdn.unam.mx/termino/ search.

Heidegger, M. (1971). Poetry, Language, Thought. New York: Harper \& Row.

Heidegger, M. (1982). On the Way to Language. New York: Harper \& Row.

Isler Soto, C. (2008). El tiempo en "Las confesiones" de San Agustín. Revista de Humanidades de la Universidad Andrés Bello, Chile, junio-diciembre: 187-199.

Kavafis, K. (1911). Viaje a Ítaca. Recuperado de: http://www.pixelteca.com/ rapsodas/kavafis/itaca.html/ http://www.lluisllach.cat/catala/itaca.htm / http://www.lluisllach.cat/catala/itaca.htm/ https://www.youtube.com/ watch?v=NtkAV0UPCVA.

Lafaye, J. (1977). Quetzalcóatl y Guadalupe. México: FCE.

Lara-Martínez, R. (2017). 7/Chicôme estudios náhuat-pipiles. San Salvador: Universidad Don Bosco-Universidad Evangélica-Alcaldía de San Salvador.

Matta. Recuperado de: http://www.artnet.com/artists/roberto-matta/.

Molina, F. (2016). Vocabulario de la lengua castellana y mexicana. Recuperado de: http://www.ven.bc.ca/prisons/Molina_Vocabulario_Puebla-1910.pdf. Marc Thovenor (Ed.), Miguel León-Portilla (Prólogo) y Javier Manrique Amao (Colaboración), México; UNAM. Recuperado de: http://www.historicas.unam. $\mathrm{mx} /$ publicaciones $/$ catalogo/ficha? $\mathrm{id}=625$. 
Navarrete Cáceres, C. (Ed.). (2013). En la diáspora de una devoción. Acercamientos al estudio del Cristo de Esquipulas. México: UNAM-IIA. Recuperado de: https://www.researchgate.net/profile/Marx_Navarro-Castillo/publication/293815144_Culto_Popular_del_Senor_de_Esquipulas_en_Tapachula_Chiapas/links/56bb94cd08ae47fa3956aa7d/Culto-Popular-del-Senor-de-Esquipulas-en-Tapachula-Chiapas.pdf.

Onetti, J. C. (1973). La novia robada. México: Siglo XXI Editores.

Ricoeur, P. (2008). Temps et récit. 3 volumes. Paris: Ed du Seuil.

Rémy, S. (1977). Diccionario de la lengua náhuatl o mexicana. México, D. F.: Ed. Siglo XXI.

Sahagún, F. B. (1978). Visión de los vencidos. México: UNAM. Miguel León-Portilla (Ed.).

Sábato, E. (1985). El túnel. Madrid: Editorial Cátedra.

Salarrué. Obras escogidas. San Salvador: Editorial Universitaria, 1969-1970. Hugo Lindo (Ed.).

San Agustín. (s.f.). Las confesiones. Recuperado de: http://www.diocesisdecanarias.es/pdf/confesionessanagustin.pdf/ http://www.biblioteca.org.ar/libros/132410.pdf/ http://faculty.georgetown.edu/jod/latinconf/latinconf.html.

Steve Miller Band. "Fly like an Eagle". Recuperado de: https://genius.com/ Steve-miller-band-fly-like-an-eagle-lyrics

Wilder, T. (2013). Heaven's my Destination (1935). New York: Harper Perennial 